\title{
A BIM-based Detailed Electrical Load Estimation, Costing and Code Checking
}

\author{
Jasim Farooq ${ }^{1}$, Paawan Sharma ${ }^{2}$, Sreerama Kumar $\mathbf{R}^{3}$ \\ ${ }^{1,2}$ School of Engineering, University of Petroleum \& Energy Studies, Dehradun-248007, India \\ ${ }^{3}$ Department of Electrical and Computer Engineering, King Abdulaziz University Jeddah-21589, Saudi Arabia
}

\begin{tabular}{l} 
Article Info \\
\hline Article history: \\
Received May 27, 2018 \\
Revised Aug 12, 2018 \\
Accepted Aug 19, 2018
\end{tabular}

Keyword:

API

Automated code-checking and

revit

BIM

Demand load

\begin{abstract}
Building Information Modeling (BIM) has established into a powerful solution for our construction requirements throughout its life cycle. Compared to conventional methods, BIM offers simple, faster and accurate methodology for modelling, estimation and analysis. In this paper, a novel Autodesk Revit add-in tool named as "Electrical System Estimation and Costing Tool"(ESECT) is proposed for the simultaneous estimation of electrical connected load, demand load, Volt Ampere per square meter, cost of electrical system construction and monthly bill from a residential building model and the add-in tool is developed by using Visual basic C\# language. Research results indicate that wide range of BIM automated tools are possible for code-checking and estimation for design analysis at all stages of electrical system development and eventually leads to better design and cost reduction.
\end{abstract}

Copyright $(9) 2018$ Institute of Advanced Engineering and Science. All rights reserved.

\section{Corresponding Author:}

Jasim Farooq,

School of Engineering,

University of Petroleum \& Energy Studies,

Dehradun-248007, India.

Email: jasimfarooq@gmail.com

\section{INTRODUCTION}

The multifaceted and lively nature of the construction industry is widely recognized and the building electrical system is one of the major inevitabilities of modern construction projects. A building electrical design is generally unique in nature and include a diverse collection of electrical loads having varying energy demand time to time. The mission of the electrical system designer is for planning and designing the optimum electrical system according to client's requirements by promulgated codes like National Electrical Code (NEC) [1]. Electrical system design having many constraints such as codes and regulations, budget allocations, tariff, comfort and client requirements and by understanding the necessities, designers conduct calculations and finalize the design for actual construction. Designers will conduct calculation and the results are depicted on drawings for preparing a conceptual model. After analyzing the total electrical loads and constraints, the optimization procedure will follow for finalizing the design. [2], [3] show that decisions made at initial phases of project planning have a solid effect on its life cycle costs. Electrical system design normally is an iterative process and revisions do generally exist. Therefore estimating electrical system load and cost and comparing it with project goals at the design stage is a necessity for design finalization, code compliance checking, energy and emission reduction studies and it is an approach that is attaining continuous attention [4]. Estimation of electrical demand load, total cost and code checking at early design stage will give an awareness about the proposed load characteristics of system design, number of transformers, tariff and budget requirements for its implementation.

Building's electrical demand load is estimated by summarizing individual electrical loads according to its load type and applying demand factors as per codes prevailed in that region like National Electrical 
Code (NEC). The building demand load assessment calculation will be varied according to the type of building and purpose of building [5]. Qualified and trained staff(s) is required for conducting code compliance, cost and load estimation. According to the nature of building, size, methodology of estimation, experience of the estimator and their numbers the time for electrical design studies will vary from a few minutes to many days. Authorities and electricity companies have mandatory regulations for permitted minimum/maximum Volt Ampere per square meter $\left(\mathrm{VA} / \mathrm{m}^{2}\right.$ ) according to the type of building and its location. A lucid idea about the proposed design load characteristics, its impact on code compliance and budget is required, that too at early design stage itself to avoid conflicts in construction stage. A bottom to top approach load study is to be conducted for getting detailed total electrical load/cost and generally it is a laborious task. As per NEC demand factor may be applied to the total connected load or according to the load type and total demand load can be written as

$$
\text { Demand Load }=\sum_{\mathrm{c}=1}^{\mathrm{n}}\left(\left(\sum_{\mathrm{i}=1}^{\mathrm{m}} \mathrm{li}\right) \times \mathrm{D}\right)
$$

Where

$$
\begin{aligned}
& \text { L : load of particular type } \\
& \text { D : Demand Factor according to load type } \\
& \text { c : Type of load }
\end{aligned}
$$

Estimation of monthly bill = Building demand load in kVA $\mathrm{x}$ load factor $\mathrm{x} 24 \times 30 \times$ unit electricity

Generally

Load factor for residential building $=10-15 \%$ and unit electricity rate is 0.18 Saudi Arabian Riyal (SR) for residential buildings up to 6000 units [6] and

Total cost $=\left(\sum_{\mathrm{i}=1}^{\mathrm{n}} \mathrm{Qi} \times \mathrm{Ri}\right)$

Where

Qi : Quantity of particular electrical item

$\mathrm{Ri}$ : Unit rate including but not limited to material, installation, wiring, overhead cost, testing and commissioning and profit margin for both electrical outlets and devices with respect to project specifications.

In traditional methods, after the design calculations, the outcomes are depicted in electrical drawings with the help of 2D CAD. After the completion of design drafting, electrical quantities are extracted manually from 2D CAD drawings and tabulated either using excel sheets or in 2D CAD itself for detailed estimation. The unit electrical load for each outlet/end loads are tabulated and necessary computations are applied for getting summarized data. According to the scale of the project, large amount of data is to be extracted and tabulated for estimating electrical loads. Significant time and money are lost due to traditional methods that relies on labor-intensive, time-consuming, error-prone and thus these are inefficient manual methods. In general, there are number of changes during planning/design phases of the building model and these changes lead to a number of tedious reworks [7], severely restricts the innovative procedure for refined design studies. Due to the lack of arithmetic interlinking between panel and load in 2D CAD, manual updating of all the data is necessary leading to more cost and time. Also each and every building design is required to go a prerequisite process of code assessment. So in order to comply with code and constraints automated tools are required, where well-defined rules can be applied automatically with minimum user intervention and are increasingly needed in construction industry [8]. Automatic code checking and load estimation have extensive range of applications in building design such as building regulatory code checking, customized checking for designers/ companies and design and safety analysis. As design is an evolving process, the interval exist between various assessment feedbacks such as load estimate, cost estimate and client valuation will make the traditional approach ineffective. There is a definite requirement for a designerfocused system that can conduct concurrent design assessment at initial stages of project development as $70-80 \%$ of construction costs are influenced by developer's choices in the early design phase [9]. By raising level of automation and evaluating quantification of design economics, monthly electricity bill and total load details at early design stage and that too will get within a few seconds without any budget requirements will positively ease electrical system design and minimize uncertainties. Cost overruns and claims can be 
minimized on our construction project agreements by refining the quality of our design model and that leads to better control over project scope and budget [10]. The tool is to be simple, should provide accurate results, fast and having zero or least user inputs. The advent of information technology based design and modelling of construction projects such as BIM offers a better solution to overcome the inefficiencies in the present method.

BIM or Building Information Modelling is a method for developing the construction projects with the support of Information and Communication Technology (ICT), the process of generating and maintaining digital information of physical and functional properties of our construction requirements. A coherent digital model of buildings where all building artifacts are realistic in nature and capable for functionally interconnect through an information system. Integrated modelling backed by information system provides automated extraction of quantities or data by using BIM authored tools. BIM collaborative concepts enable whole building integrated analysis for optimizing actions and adding more value to our assets [11]-[13]. Nowadays BIM has become indispensable for proper modelling and analysis of infrastructural and building projects in many countries [14]. BIM has advanced into an authoritative solution for visualizing and analyzing various aspect of construction such as nth dimensional modelling, coordination and engineering studies, whole building energy and renewable energy potential analysis and even real time smart built analysis from its conceptual stage to demolition. BIM is a significant advancement for accurate estimation and for generating immediate alternatives. The increasing adoption of BIM in the electrical trade is changing the way of electrical system planning, modelling, design, calculations and estimation [15], [16]. Advancements in BIM offers a plethora of possibilities for new generation of software tools that can automate the electrical system design and analysis of construction projects. BIM authored tool can extract pertinent information directly from BIM models and by processing the extracted data the necessary calculations can be done. The semantic information system based parametric modelling is the key behind the BIM based integrated studies such as the precise estimation, clash detection, integrated analysis and whole building energy analysis.

One of the features of BIM applications in the construction industry is to facilitate various code checking and simulations for assessing building designs in the prior stages of a project development [17]. It is possible to embed some rules in BIM application parametric design systems but certain condition require specific tool development such as customized rule checking according to localized requirements and costing [18]. Automated tools will study the conditions according to user requirements by assessing the given model, and return the results through a user-interface, such kind of automated checking can provide necessary information more speedily and reliably by BIM based methods [17], [19]. Most of the matured BIM applications offer a user developer options for automating repetitive tasks and extracting customized results from BIM model. A BIM authored tool can be developed by an Application Programming Interface (API) method or by a standalone application, where BIM model is to be exported with certain kind of file format for analysis or by a web-based application suitable to conduct necessary user defined calculations [20]. The later methods requires a seamless interoperability without data loss and the Industry Foundation Classes (IFC) is the most successful format for exchanging data between BIM applications [21]. API based add-in application doesn't have interoperability issues, because it extracts the necessary data directly from the same BIM platform.

There are many matured applications for BIM based modelling such as Graphisoft's ArchiCAD [22] and Autodesk's Revit [23] and as per present conditions, Revit is one of the widely used BIM application [24]. For this study Revit 2017 platform and its Software Development Kit (SDK) is used for developing add-in tool. By using Revit API platform developers can access geometrical and parameter data of the building model and it is possible to create or edit model elements. The Revit API offers a mechanism for filtering and filters are capable to extract precise set of elements according to the requirements. Filtered elements can be collected in a list for further processing. Using languages compatible with Microsoft .Net framework like Visual Basic or Visual C\# it is possible to fully access Revit Platform API. Revit API, by default provided large number of built-in-parameter retrieving options, which are defined in Autodesk. For the purpose of information extraction, the pre-existing families, class, category, types of parameters and types of elements are studied in order to understand the kind of data to be extracted. One of the major requirements for automated estimation is the classification of artefacts according to its types, and this method is known as WBS (Work Breakdown Structure) to use to avoid conflicts and omissions. One of the WBS available is OmniClass, is to unequally classify into certain type of items, for an example OmniClass number "23-35 13 00" stands for transformers [25]. Revit families have built in provision for OmniClass number. For this addin tool development, Volt Ampere (VA), OmniClass number, phase and unit cost parameter values of all the electrical devices and outlets are to be extracted for calculations from BIM electrical model.

This paper describe, an Autodesk's Revit add-in application developing methodology for estimating electrical load and density, costing and monthly bill for a residential building BIM models and using NEC rules. The Autodesk Revit add-in tool named as "Electrical System Estimation and Costing Tool"(ESECT) 
tool proposed in this paper assists electrical designers for automatically performing necessary calculations for decision making at early phases of design and to validate their model and minimizing changes at later stages of design. As shown in Figure 1, this tool simultaneously provides necessary data in few seconds and thus minimizing estimation time and error by providing faster feedback about the design.

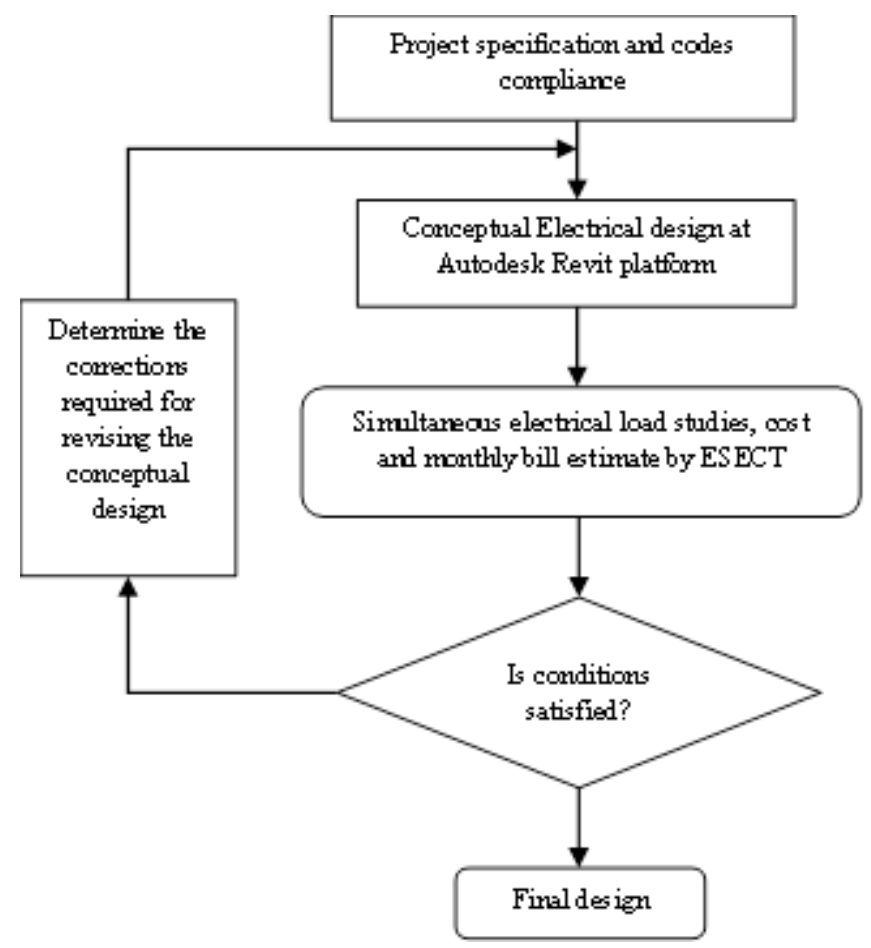

Figure 1. Iterative optimization of electrical system design by ESECT

The add-in tool is to estimate total electrical load from individual electrical fixtures and devices and not from panel board. Hence an electrical BIM model without completing panel studies can also be used for calculations. Literature review is addressed in Section 2. Section 3 presents proposed methodology. In Section 4, a case study and its inferences are discussed. Paper concludes with Section 5.

\section{LITERATURE REVIEW}

The capabilities and usage of BIM are well documented in the literature [17]. As per the present conditions, BIM is the finest way to automate quantity take off [26]. Even though many efforts are already conducted for BIM based cost estimation, calculations and automatic code checking for systems such as energy analysis, water distribution network and HVAC, the studies related to electrical trade are limited. There exists a lag in BIM usage related to electrical system design and build [27]-[31]. Methods to estimate electrical demand load, rules for demand factors and permitted VA per square foot are widely documented by authorized agencies such as NEC and IEC. Previous studies show that the initial design concepts and decisions can considerably impact the total load and life cycle cost of buildings. Also, design purely based on insight and experiences are likely to be error-prone [32]. While we pass through the traditional drafting method of design studies, the difficulties of 2D CAD methods have also been studied by previous researches and major drawbacks such as problems in coordination, omissions, lack of parametric modelling and manual method for estimation are identified [17], [33], [34]. Traditional 2D drawings are developed by a manual process; incorrect inputs and wrong interpretations therefore usually exist. Also it is very hard to process intricate situations such as connections and functional relationship between various building artefacts. The undesirable outcomes of combining 2D estimation and 2D based designs intensify the probabilities of cascading mistakes and omissions happening during the various stages of the project, which may eventually lead to incorrect cost estimations [35]. BIM has evolved to mitigate these problems associated with 2D methods. 
The notion of automating the code checking for construction has been there for more than two decades [36]. Many authentic studies related to BIM based code checking, estimation and costing are conducted. API, standalone application and web based methods are the kind of BIM authored tools developed by researchers and in this methods, new applications are developed by using programming languages such as Visual Basic and $\mathrm{C \#}$. The major studies related to building design rule-based code checking have been explored, reviewed and summarized in [18]. In 2010 Georgia Institute of Technology presented a BIM based automated construction safety rule checker [37], [20] has developed an automated code-checking application for water networks by incorporating IFC, for HVAC [38] and automated safety rule checking [39], [40] has proposed a framework which is capable to retrieve information from Autodesk Revit platform for the building envelope's energy code compliance checking. Similar to code checking, cost estimation is also one of the most critical task for construction projects and it is both time-consuming and error-prone due to working complexity and conventional 2D CAD based modelling [41] and while deploying BIM, most of the applications capable to provide quantity estimation but manipulation of data is not possible, so specialized tool is required for cost estimation [10] and user preferred calculations. Cost estimation can be for conceptual (at planning stage) or schematic (at schematic design phase) or detailed (at design phase) estimation [42], [43] has proposed a cost estimation method named Low Impact Design Explorer (LIDX) for schematic BIM models at its conceptual phase by using Google SketchUp environment [44] has developed an ontological inference for BIM based cost estimation to find the most suitable work item and their cost.

Currently several add-in tools are existing for extracting information from REVIT BIM model that are developed by different ventures or individuals. As per Autodesk add-in page there exist tools for handling specialized tasks such as adding electrical power cables, extracting panel schedules and Schneider's layoutFAST have been developed [45]. All these add-in/plugins are either free or paid, and related application developing methods are hidden. Further, there is no application related to electrical load estimation and code checking for electrical BIM Revit models that is reported in the literature. The following section discusses the development of ESECT. The problems associated with automated quantity extraction and costing are discussed in Section 4 along with the steps for better the development and standardization of BIM based automated tools.

\section{PROPOSED METHODOLOGY}

ESECT development has three steps of programming as shown in Figure 2. In the first step major programming is done at Microsoft visual C\# platform. In step-2, necessary programming for creating new add-in button at Revit's add-in panel is done at Microsoft Visual C\# platform. In step-3, the registration of the program written in steps 1 and 2 is done by writing a manifest file inMicrosoft note file and saving it as “addin" file. By following these steps ESECT add-in program can be added to Revit as shown in Figure 3. Following sub-sections give the details of these steps [46].

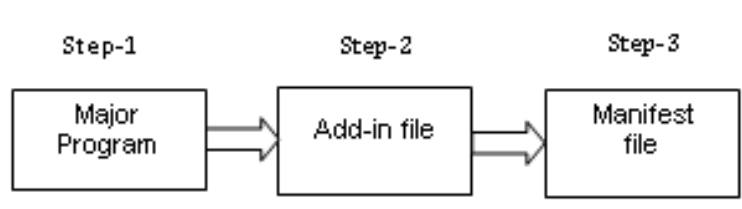

Figure 2. ESECT programming steps

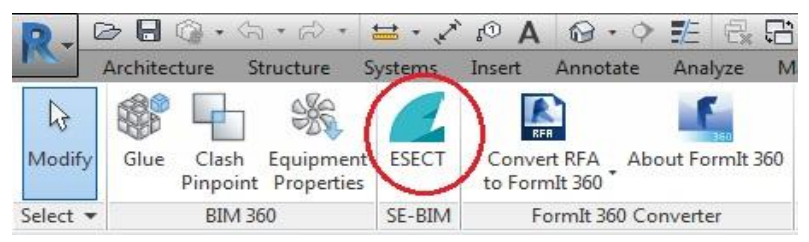

Figure 3. ESECT button Autodesk's Revit opening screen

Step 1: The first step for developing a C\# program with Visual Studio is by selecting a project type and creating a new Class Library and saving the file at proper location. Referencing with Revit is done by using "Add reference" at Solution explorer, selecting the two interface DLL files "RevitAPIUI.dll" and 
"RevitAPI.dll" from Autodesk program file stored at Revit product installation sub-folder in the computer. Graphical User interface is developed by Windows form designer as given in Figure 4 and Figure 5 shows the flowchart of the programming. Table 1 details the message box pop-ups used in the flowchart shown in Figure 5. Table 2 gives the details of the extracting methods for various parameters described in step-1. After writing necessary Revit database file linking, defining data types, the proposed methodology consists of the following procedural steps.

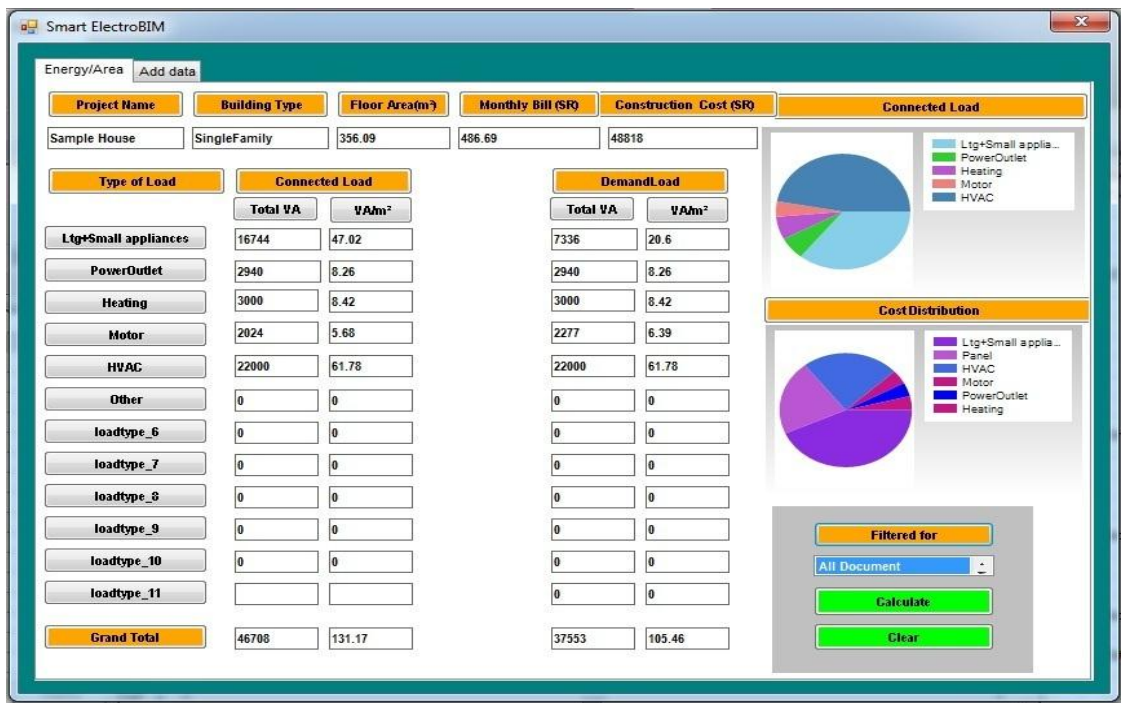

Figure 4. Simulation of ESECT for the case study

Step1.1: Check whether the model's electrical devices or connector count is equal to zero. If "No" go to step 1.2 , else end the process.

Step1.2: Estimate the total built up area of the building by extracting and summing all spatial element's and wall's bottom face area from architectural model.

Step 1.3: Collect all lighting and electrical components to a list.

Step1.4: For each lighting and electrical components extract the built-in-parameters load classification, OmniClass number, Volt Ampere value, material cost and phase of circuit.

Step1.5: Sum the load VA according to load classification. Include all end electrical end loads and exclude VA for panel board, transformer and generators to avoid double counting.

Step1.6: From material cost extracted at Step-1.4, determine total cost for supply, installation, wiring of electrical outlet, testing and commissioning and profit by referring cost database. The values of OmniClass, material cost, VA, Phase are used for finding unit total rate from database which is based on historical data. Sum the individual total cost for making grand total.

Step1.7: Apply demand factor by using arithmetic and logic coding by identifying the extracted load type name. For example "Lighting" load type demand factor is by NEC table 220.42. Calculate VA/square meter by dividing individual total load according each load type by total area of building. Display all results and the sectorial connected load and cost using a pie chart. If $\mathrm{VA} / \mathrm{m}^{2}$ does not comply with the code, a message is shown. For example NEC rule for lighting load VA/m $\mathrm{m}^{2}$ is by Article \# 220.12. The calculated value is compared with the NEC rules and the results are displayed by a message box if not complied.

Table1. Details of Message Boxes used in the Flowchart shown in Figure 5

\begin{tabular}{ll}
\hline Message Box \# & Condition for pop-up \\
\hline M1 & $\begin{array}{l}\text { Pop-up, if BIM model's electrical connector/devices count is equal }=0 . \\
\text { Pop-up, if load classification does not match with the predefined information with total } \\
\text { number of unmatched items. } \\
\text { M3 }\end{array}$ \\
P4 & Pop-up, if any material does not have material cost with total number of item cost missing. \\
\end{tabular}


Table 2. Details the Method of Parameter Extracting from BIM Model

\begin{tabular}{|c|c|}
\hline Information extraction step & Method \\
\hline Building Type & From "EnergyDataSettings" extract "BuildingType"; \\
\hline Floor area & $\begin{array}{l}\text { Filter all spatial elements and add it to a Collector. For each elements in the collector, extract } \\
\text { the area. Similar to this, collect all walls and extract bottom face area. Sum all individual } \\
\text { spatial and bottom face area for getting total floor area. The area is to be converted from } \\
\text { square feet to square meter, as Revit store the area in square foots. }\end{array}$ \\
\hline Filtering electrical elements & $\begin{array}{l}\text { By using "ElementCategoryFilter" and filtering "BuiltInCategory". After filtering collecting } \\
\text { the elements to a list. }\end{array}$ \\
\hline Volt-Ampere & $\begin{array}{l}\text { An element from the collected list search for parameter "Electrical Data". Split and extract the } \\
\text { Volt-Ampere part. Same method applies for the determination of the number of phases of the } \\
\text { electrical loads. }\end{array}$ \\
\hline Material Cost & $\begin{array}{l}\text { An element from the collected list find "ALL_MODEL_COST" built in parameter properties } \\
\text { by using "get_Parameter". }\end{array}$ \\
\hline OmniClass Code & $\begin{array}{l}\text { An element from the collected list find "OMNICLASS_CODE" built in parameter by using } \\
\text { "get_Parameter" link. }\end{array}$ \\
\hline
\end{tabular}

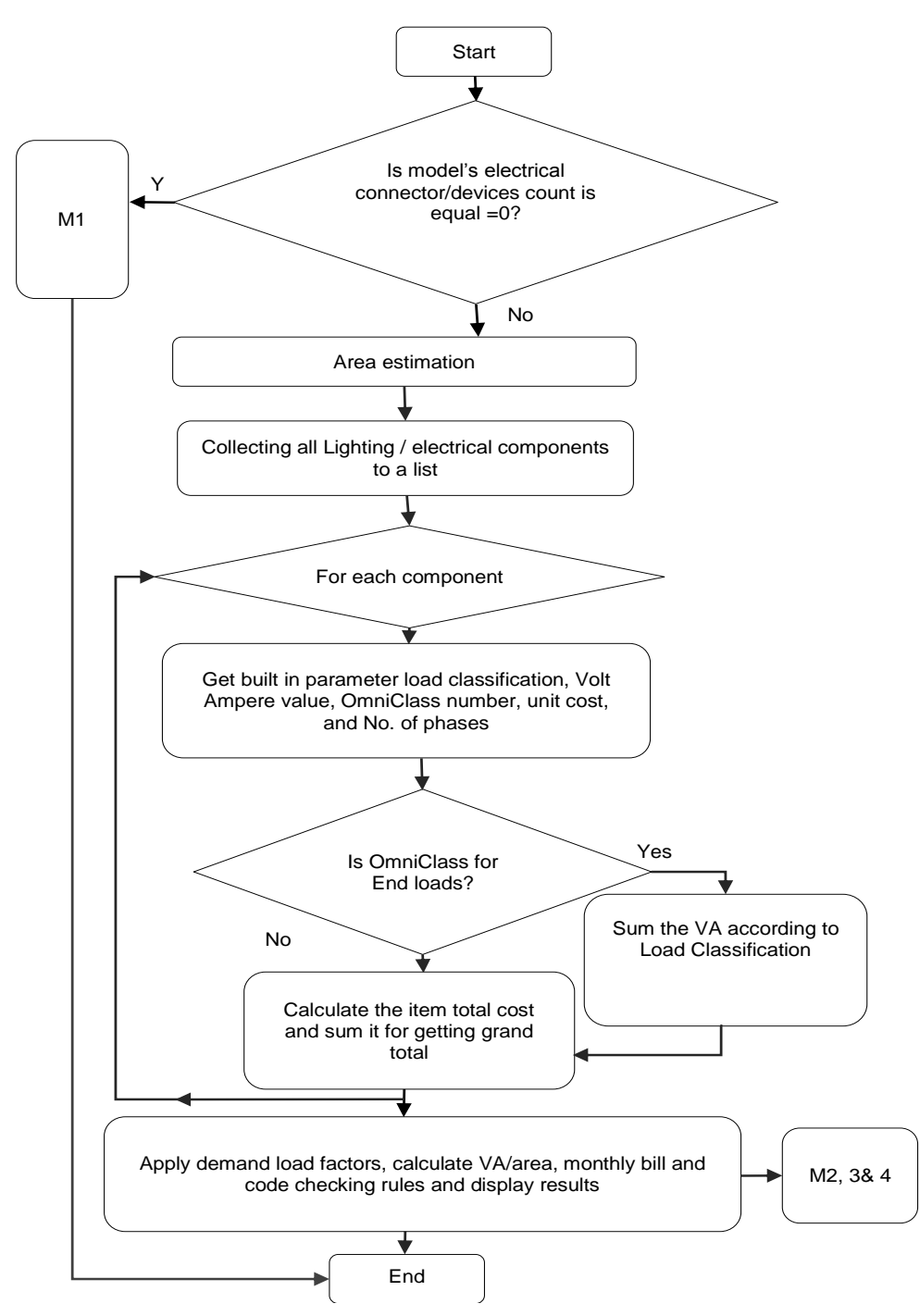

Figure 5. Flowchart of C\# programming for developing BIM based load estimation tool (for Step-1) 
Step 2: In this step necessary programs for creating a new button at Revit's Add-Ins ribbon panel is done using Microsoft Visual C\# platform. The path details of step-1 and an icon file details for the button is done in this step.

Step 3: This step involves the development of a manifest file for registering the program developed in step-1 in Visual studio into Revit. Necessary programming is done in Notepad and saved as ".add-in file". Then the add in file is saved at appropriate application data location (here @ C:IUserslEngj\AppData\Roaming \Autodesk\Revit\Addins 2017 ) to read automatically by Revit program during start-up. The manifest file contains details such as full path details for the add-in assembly file of Step-2. By doing these steps, in the Revit application ESECT add-in can be created at Revit.

\section{CASE STUDY AND DISCUSSION}

A BIM electrical model is developed by using the sample BIM file provided with Revit and is shown in Figure 6. Systems such as lighting, sockets, appliances, HVAC and panel board are developed for this residential building model. All the element families are predefined with material cost and OmniClass. All the load types of families are matching with predefined values of ESECT. The calculation results are relatively accurate compared with the traditional method. The average time required for the calculation of electrical load density is around 4 seconds using Autodesk Revit 2017. Predefined families and modelling according to ESECT gives good results, but when we generalize ESECT, following details are to be considered.

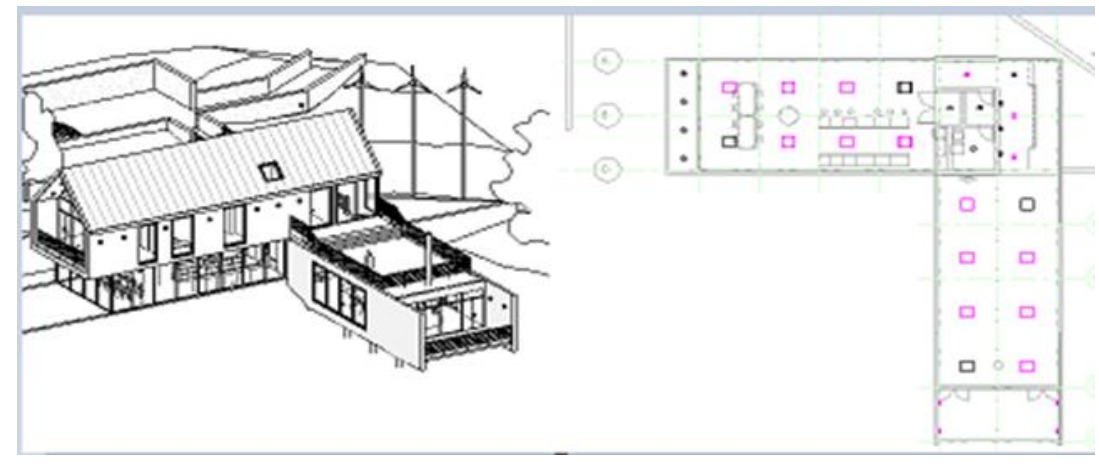

Figure 6. Developed case study

The major process in an automated BIM tools are (a) extraction the exact items as specified by the user (b) Identification of the extracted material with all its specifications (c) processing of the information and generation of the results accurately. BIM based automated code-checking tool is a proficient method for building design assessment; however, development of an effective and robust interfaces has many technical concerns [47]. Currently, many corporate follows their own customized modelling for families and costing methods according to their priority and requirements. Estimators follow different methods leading to troubles between counting. Nonexistence of official methods is the major cause of this problem [35]. The extraction process is the key function which will determine the degree of accuracy and capability of add-in tools. There must be uniformity in BIM modelling to develop an automated tool to extract the necessary data without errors. So a standardized method for electrical families is required for efficient BIM authored tool for electrical studies. Authorities are to bring regulations for BIM modelling so that the designers can follow a common method for modelling, designing and quantity take off such that an automated tool can work well in all platforms without errors. Hence in this paper, a predefined set of families for the case study development is used in accordance with ESECT. How to interpret existing human-oriented language written codes to machine interpretable manner is also a concern for the development of the programs as it requires expert level of knowledge. Dealing with the complex building construction rules and the level of conditions needed to be applied are the major challenges for successful code checking implementation [48]. For example demand factor will vary according to the type of building, type and magnitude of load. Currently ESECT is capable to calculate demand factor for residential building, but it is possible to add other codes by developing appropriate algorithms.

All kinds of historical cost data is currently available with traditional methods, so the important issue is the capability of an automatic tool is to precisely identify the object and related information from BIM model and match it with the cost database for getting exact information. Material cost and electrical 
outlet cost is to be calculated for generating total cost of electrical construction. But necessary information related to cost estimation may not be provided by BIM, in such cases ontological approaches similar to [44] is required to overcome the problem of cost estimator's subjective decisions and ontological approach is to be compatible with existing electrical estimation methods. Ontological procedure brings material prices from cost database according to material specification. But the best method is predefining material cost. For example to estimate the total cost for panel board the details such as number of ways, type of circuit breakers, level of Ingress Protection and automation requirements may not be available for the determination of the prices at tendering stage, so ontological procedure may lead to error. In the case of electrical outlet cost, it varies according to the conditions such as distance from the panel board, height from the floor and type of project area. So a combined effort of predefined material pricing and ontological methods is required for electrical outlet costing.

Various feature that are to be incorporated in BIM modelling and algorithms are as follows:

a. Predefined family modelling according to common standards with prices is required and in line with automated tool's settings for extracting data. Specific type of electrical parameters is to be added at BIM families for all kinds of electrical specifications and calculations.

b. Appropriate ontological stance for electrical estimation is required according to contextual information and approved procedures for getting refined and accurate estimation.

c. Uniqueness of construction, scope of the work and complexities in quantity take off and costing maybe wrong without human intervention. Continuous efforts are required to standardize a BIM based automation tool

In this paper, a procedure as shown in Figure 7 is proposed for the development of a better methodology for standardization of BIM based automated estimation and costing process for electrical systems. It is proposed to have a sub WBS unique number. For example a 30A, 3phase, 400V, NEMA-3 disconnect switch unique number can be given by as "30.3.400.N3.NF.ST.NG.R100.04" and the details of this unique number is given in Table 3. This number either given as a new data or set to be extracted from BIM families by following an algorithm. WBS number and sub WBS number can ease the automation procedure. This code number can help to identify the BIM family easily without an error. As shown in Figure 7, the automation tool is to generate detailed results in excel file with itemized quantity and calculation/ pricing methodology along with the associated formula, so that an expert rationale can cross check and adjust the results if any mistake in modelling or automated tools or both is felt. For every project the required feedback is to be given to families, modelling methodology and the automation tool. Hence, as the number of projects increases, the reliability of BIM based automation tool also increases and it get standardized for a company.

Table 3. Example of Sub WBS Unique Number “30.3.400.N3.NF.ST.NG.R100.04” Implies

\begin{tabular}{ll} 
Description & Specification \\
\hline Ampere & $30 \mathrm{~A}$ \\
Phase & 3 Phase \\
Voltage & $400 \mathrm{~V}$ \\
NEMA Rating & NEMA3 \\
Fused? & No \\
Material & Steel \\
With Gasket? & No \\
Recycle? & $100 \%$ \\
Energy star & 04 \\
\hline
\end{tabular}




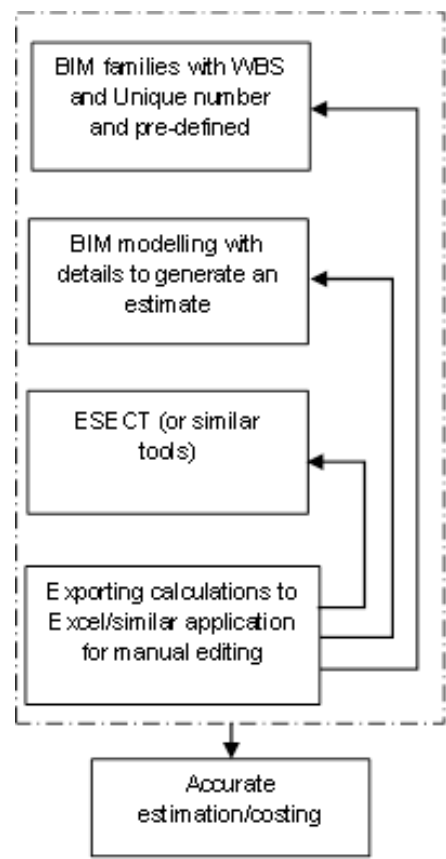

Figure 7. A methodology for standardizationof the BIM based automated tools for estimation, costing and code checking

\section{CONCLUSION}

A BIM based electrical demand load estimation, VA/ m2 code checking and costing add-in tool for residential building's Autodesk Revit model has been presented in this paper. This tool offers a faster, accurate and simpler method compared to the existing traditional approach and redundant works become much easier for vitally important tasks. The practicality and the associated complexities of the method has been shown by a case study. The existence of fully automated estimation and code checking increases the efficiency of designers and they can focus on what really matters for construction, such as cost reduction, energy efficiency, safety and sustainability. This tool potentially provides significant value for electrical designers and can lead to a widespread use of BIM for electrical trade. Further research is required to develop ontological inferences for more accurate identification of the system elements.

\section{REFERENCES}

[1] “NFPA 70: National Electrical Code®”, Nfpa.org, 2017. [Online]. Available: http://www.nfpa.org/codes-andstandards/all-codes-and-standards/list-of-codes-and-standards/detail?code=70. [Accessed: 25- Oct- 2017].

[2] Dahl, et al., "Evaluating Design-Build-Operate-Maintain Delivery as a Tool for Sustainability", Construction Research Congress 2005, 2005.

[3] K. Lam, et al., "SEMPER-II: An Internet-based Multi-domain Building Performance Simulation Environment for Early Design Support", Automation in Construction, vol. 13, no. 5, pp. 651-663, 2004.

[4] N. Fumo, "A Review on the Basics of Building Energy Estimation", Renewable and Sustainable Energy Reviews, vol. 31, pp. 53-60, 2014.

[5] P. Bunnoon, "Electricity Peak Load Demand using De-noising Wavelet Transform integrated with Neural Network Methods," International Journal of Electrical and Computer Engineering (IJECE), vol. 6, no. 1, p. 12, Jan. 2016.

[6] "Saudi Electricity Company", Se.com.sa, 2017. [Online]. Available: https://www.se.com.sa/enus/customers/Pages/TariffRates.aspx. [Accessed: 19- Dec- 2017].

[7] M. Rajabi, et al., "Cloud based BIM Solution for Tender Estimation Regarding Mechanical Electrical and Plumbing (MEP) Trades", in 5th International/11 th Construction Specialty Conference, Vancouver, 2015.

[8] N. Nawari, "The Challenge of Computerizing Building Codes in BIM Environment", Proceedings of the 2012 Asce International Conference on Computing in Civil Engineering, Clearwater Beach, Florida; Jun 17-20, 2012.

[9] A. Bhimani and P. Mulder, "Managing Processes, Quality, and Costs: A Case Study", Journal of Cost Management, vol. 15, no. 2, pp. 28-32, 2001.

[10] V. Bazjanac, "Model based Cost and Energy Performance Estimation during Schematic Design", Berkeley: Lawrence Berkeley National Laboratory, University of California, 2005.

[11] Suermann, P. C., "Evaluating the Impact of Building Information Modeling (BIM) on Construction", University of Florida, 2009. 
[12] R. McPartland, et al., "What is BIM?", NBS, 2017. [Online]. Available: https://www.thenbs.com/knowledge/whatis-building-information-modelling-bim. [Accessed: 25- Oct- 2017].

[13] Enegbuma, W. I, et al., "Building Information Modelling Penetration Factors in Malaysia", International Journal of Advances in Applied Sciences, vol. 3, no. 1, pp. 47-56, 2014.

[14] "Government Construction Strategy 2016-20 March 2016", The Infrastructure and Projects Authority, gov.uk, 2016.

[15] J. Farooq, P. Sharma and S. Kumar R, "Applications of Building Information Modeling in Electrical Systems Design", Journal of Engineering Science and Technology Review, vol. 10, no. 6, pp. 119-128, 2017.

[16] C. Wang, S. Hammed Adetola and H. Abdul-Rahman, "Assessment of BIM implementation among MEP firms in Nigeria", Iaescore.com, $2015 . \quad$ [Online]. Available: http://iaescore.com/journals/index.php/IJAAS/article/view/862/5794. [Accessed: 27- May- 2018].

[17] C.M. Eastman, P. Teicholz, R. Sacks, K. Liston. BIM Handbook: a Guide to Building Information Modeling for Owners, Managers, Architects, Engineers, Contractors, and Fabricators, 2nd ed. John Wiley and Sons, Hoboken, NJ, 2011.

[18] C. Eastman, J. Lee, Y. Jeong and J. Lee. "Automatic rule-based checking of building designs", Automation in Construction, vol. 18, no. 8, pp. 1011-1033, 2009.

[19] L. Ding, R. Drogemuller, M. Rosenman, D. Marchant, J. Gero. Automating code checking for building designs, in: K. Brown, K. Hampson, P. Brandon (Eds.), Clients Driving Construction Innovation: Moving Ideas into Practice, CRC for Construction Innovation, Brisbane, Australia, 2006, pp. 113-126.

[20] Martins, J.P., and Monteiro, A.. "LicA: A BIM based automated code-checking application for water distribution systems." Automation in Construction, 2012.

[21] "IFC Overview summary - Welcome to buildingSMART-Tech.org", Buildingsmart-tech.org, 2017. [Online]. Available: http://www.buildingsmart-tech.org/specifications/ifc-overview. [Accessed: 25- Oct- 2017].

[22] Graphisoft (retrieved on 12th Dec. 2017). What is ARCHICAD? [Online]. Available: http://www.graphisoft.com/archicad/

[23] Autodesk. (retrieved on 12th Dec. 2017). Revit, Built for BIM, [Online]. Available: http://www.autodesk.com/products/revit-family/overview.

[24] R. McPartland and R. McPartland. "NBS National BIM Report 2017”, NBS, 2017. [Online]. Available: https://www.thenbs.com/knowledge/nbs-national-bim-report-2017. [Accessed: 07- Dec- 2017].

[25] Omniclass.org, 2017. [Online]. Available: http://www.omniclass.org/tables/OmniClass_23_2012-05-16.zip. [Accessed: 02- Dec- 2017].

[26] A. Sattineni and R. Bradford II, "Estimating With Bim: A Survey of Us Construction Companies", Auburn: McWhorter School of Building Science, Auburn University, 2011.

[27] J. Zhou, et al., "Discussion of State of Practice of Building Information Modeling in the Electrical Construction Industry", by Awad S. Hanna, Michael Yeutter, and Diane G. Aoun, Journal of Construction Engineering and Management, vol. 142, no. 3, Mar 2016.

[28] Salman Azhar and Seth Cochran,"Current Status of Building Information Modeling (BIM) Adoptability in the U.S. Electrical Construction Industry”, in Fifth International Conference on Construction in the 21st Century, Istanbul, Turkey, pp. 1387-1394, 2009.

[29] J Zhang et al., "Building Information Modelling for Smart Built Environments", in Proc. Building A Better New Zealand, 2015 @ MDPI.

[30] Wei Wu, et al., "GIS-BIM Based Virtual Facility Energy Assessment (VFEA) - Framework Development and Use Case of California State University", in Computing in Civil and Building Engineering, 2014 ( ) ASCE.

[31] Awad S. Hanna, et al., "State of Practice of Building Information Modeling in the Electrical Construction Industry", Journal of Construction Engineering and Management, vol. 140, no. 12, Dec 2014.

[32] S. Fenves, et al., "SEED-Config: A Tool for Conceptual Structural Design in a Collaborative Building Design Environment", Artificial Intelligence in Engineering, vol. 14, no. 3, pp. 233-247, 2000.

[33] G. Lea, "Investigating the 'triple bottom line': CAD vs BIM. Department of the Built and Natural Environment", University of Central Lancashire, Preston, UK, 2011.

[34] G. Lee, et al., "Specifying Parametric Building Object Behavior (BOB) for a Building Information Modeling System", Automation in Construction, vol. 15, no. 6, pp. 758-776, 2006.

[35] A. Monteiro and J. Poças Martins, "A Survey on Modeling Guidelines for Quantity Takeoff-oriented BIM-based Design", Automation in Construction, vol. 35, pp. 238-253, 2013.

[36] C. Dym, et al., "A Knowledge-based System for Automated Architectural Code Checking”, Computer-Aided Design, vol. 20, no. 3, pp. 137-145, 1988.

[37] S. Zhang, et al., "Integrating BIM and Safety: An Automated Rule-based Checking System for Safety Planning and Simulation", Proceedings of CIB W099, Washington D.C., August 24-26, 2011.

[38] X. Liu, et al., "Domain-specific Querying Formalisms for Retrieving Information of HVAC Systems", J. Comput. Civ. Eng., vol. 28, no. 1, pp. 40-49, 2014.

[39] S. Zhang, et al., "Building Information Modeling (BIM) and Safety: Automatic Safety Checking of Construction Models and Schedules", Automation in Construction, vol. 29, pp. 183-195, 2013.

[40] S. Sinha, et al., "Extracting Information from Building Information Models for Energy Code Compliance of Building Envelope", 2013. 
[41] Z. Ma, et al., "Semi-automatic and Specification-compliant Cost Estimation for Tendering of Building Projects based on IFC Data of Design Model", Automation in Construction, vol. 30, pp. 126-135, 2013.

[42] P. Vaidya, et al., "Integrated Cost-estimation Methodology to Support High-performance Building Design", Energy Efficiency, vol. 2, no. 1, pp. 69-85, 2008.

[43] F. Cheung, et al., "Early Stage Multi-level Cost Estimation for Schematic BIM Models", Automation in Construction, vol. 27, pp. 67-77, 2012.

[44] S. Lee, et al., "Ontological Inference of Work Item based on BIM Data", KSCE Journal of Civil Engineering, vol. 19, no. 3, pp. 538-549, 2014.

[45] "Electrical Design | Plugin, Add-on, Extension for Revit | Autodesk App Store", Apps.autodesk.com, 2017. [Online].

Available: https://apps.autodesk.com/RVT/en/List/Search?facet=_category\%3a\%3aElectrical+Design\&page=1. [Accessed: 31- Oct- 2017].

[46] Thebuildingcoder.typepad.com, 2017.

[Online].

Available: http://thebuildingcoder.typepad.com/files/revit_2014_api_developer_guide.pdf. [Accessed: 02- Dec- 2017].

[47] J.-K. Lee, et al., "Development of Space Database for Automated Building Design Review Systems", Automation in Construction, vol. 24, pp. 203-2012, 2012

[48] W. Solihin and C. Eastman, "Classification of Rules for Automated BIM Rule Checking Development", Automation in Construction, vol. 53, pp. 69-82, 2015. 